\title{
Shock-induced facilitation of a partially extinguished CER'
}

VERNON L. QUINSEY and JOHN J. B. AYRES, University of Massachusetts, Amherst, Mass. 01002

A CER to a light CS was acquired by 22 rats and partially extinguished. Half the $S$ s were then given seven free shocks before another extinction session. The noncontingent shock group subsequently showed more suppression of lick rate to the CS than did the no-shock group. Experiment 2 determined that the CER in Experiment 1 was not due to pseudoconditioning and that the CS facilitated licking in $S$ s with completely suppressed baselines.

The present experiments were designed to replicate Hoffman's (1965) finding of shock-induced facilitation of a partially extinguished CER in a paradigm similar to that used by Quinsey \& Ayres (1969).

\section{EXPERIMENT 1 \\ Subjects}

The Ss, 24 naive, male Sprague Dawley rats, were 85 to 90 days old when received from Dennen Animal Industries, Gloucester, Massachusetts. They were maintained on ad lib food and water for seven days and subsequently reduced to and kept at $80 \%$ of their free-feeding body weight. For seven days prior to the experiment Ss were on a 24-h feeding schedule and were weighed daily.

\section{Apparatus}

The apparatus was the same as that used by Quinsey \& Ayres (1969). Briefly, it consisted of six Gerbrands' operant conditioning chambers with dipper feeders from which lick rate could be monitored. An increase in the intensity of light from a pilot lamp located over the dipper served as the CS. The US was scrambled shock provided by Grason-Stadler shock sources.

\section{Procedure}

Prior to the first experimental session, Ss were taught to lick $16 \%$ sucrose solution from a dipper. The dipper was accessible to Ss for the first $3 \mathrm{sec}$ in every 5 -sec period in all sessions where it was used. The remainder of the experiment consisted of five sessions: habituation to the light, light-shock pairings, recovery of lick rate, partial extinction of fear to the light, and a further extinction or testing session preceded either by free shocks or no free shocks. Ss were arbitrarily assigned to two equal groups that were treated differentially on the final day of the experiment: Group FS1 received noncontingent or free shocks prior to testing with the CS, but Group SR did not, thus serving as a control for spontaneous recovery. On the conditioning day all Ss received 10 presentations of a $15-\mathrm{sec}$ light $\mathrm{CS}$ that coterminated with a $1-\mathrm{mA}, 1-\mathrm{sec}$ shock. The conditioning session was 22-min and 40-sec in duration, and the CSs were separated by a variable intertrial interval (VITI) of 2-min. The dipper was not presented during this session. On the testing day all Ss were placed in the apparatus for a 15-min, 47-sec period with no dipper presentations. During this time the FS1 Ss received seven 1-sec, .8-mA shocks with a 2-min VITI. Dipper presentations then began $100 \mathrm{sec}$ after the last shock. Group SR was treated similarly but received no shocks. There were 1-min CS presentations in the 10th and 13 th minute of habituation, extinction, and the last half of testing. All of these sessions and the recovery session were $15 \mathrm{~min}$ long.

Results and Discussion

The data are presented in Fig. 1. As can be seen by the difference between the FSI and SR Ss in testing, the noncontingent shock had the expected facilitating effect.
After the free shock in testing, 4 of the 12 FS I Ss stopped licking altogether; in addition, one $S$ from each group stopped licking after CER training. Data from Ss not responding at all in a session were not considered for that session in the analysis or in Fig. 1. A comparison between FSI and SR Ss on the first $C S$ in testing was significant $(F=10.96, d f=1 / 16, p<.005)$. But the noncontingent shock did not actually enhance suppression, it merely arrested extinction, because the FSI group did not suppress more to the first CS in testing than it did to the last $\mathrm{CS}$ in extinction $(\mathrm{F}<1)$. Figure 1 clearly shows no spontaneous recovery of the SR Ss' suppression ratios in testing. The remaining results will be presented with those of the final experiment.

\section{EXPERIMENT 2}

The purpose of Experiment 2 was to replicate the finding of the previous experiment with reference to the FS1 group while adding a control for pseudoconditioning.

\section{Subjects and Apparatus}

Twenty-two Ss similar to those described in Experiment 1 were run in the same apparatus as used previously. Preexperimental treatment of $S s$ was the same as in Experiment 1.

\section{Procedure}

Subjects were assigned arbitrarily to two equal groups. Group FS2 was treated identically to Group FS1 of Experiment 1. Group PC differed from FS2 only in its treatment on the CER conditioning day. Instead of receiving CS-US pairings, Group PC was given $1015-\mathrm{sec}$ light CSs and 10 $1-\mathrm{sec}, 1-\mathrm{mA}$ shocks occurring randomly with respect to each other in a 22-min, 30-sec session.

\section{Results}

Figure 1 shows that both Groups PC and FS2 suppressed less to the CS after the free shock than they did before it. The supernormal ratios of Group FS2 clearly do not replicate the results obtained with FS1. A two-tailed Wilcoxon Rank Suns Test showed the difference between Groups FS1 and FS2 on the first CS in testing to be reliable at the .05 level. Related to this discrepancy between the results of Groups FSI and FS2

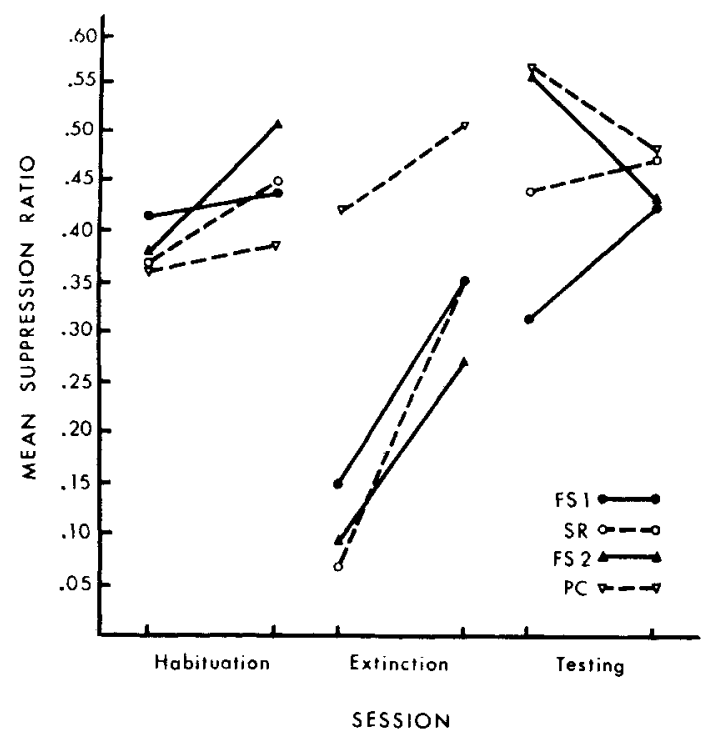

Fig. 1. Mean suppression ratios of all groups in both experiments for each CS presentation. 
were differences in the effects of free shock on their baseline response rate; a two-tailed Wilcoxon Rank Sums Test showed that latency to the first lick in testing was longer in Group FS2 than in Group FS1 $(p<.01)$. This difference in latency was measured among Ss who made at least one lick in that session. Three Ss in Group FS2 and one in Group PC stopped responding after the first shock session and another FS2 S stopped after the free shock in testing, so that there were 11 SR Ss, 10 PC Ss, 7 FS1 Ss, and 7 FS2 Ss licking in the final session.

An analysis of variance on the habituation and extinction data for both experiments yielded highly significant evidence of learning and within-session extinction. The lack of pseudoconditioning was indicated by a significant Groups by Days interaction $(F=9.4, \mathrm{df}=3 / 34, \mathrm{p}<.001$ ).

\section{GENERAL DISCUSSION}

This attempt to facilitate a partially extinguished CER with free shock was made in order to rule out an interpretation of the failure to find any enhancement of suppression by inducing fear with free CS presentations (Quinsey \& Ayres, 1969) as merely being due to procedural differences between that experiment and Hoffman's (1965) study. While some evidence of facilitation was found in Experiment 1, the effect was not replicated in Experiment 2. These discrepant results may be due to the differential effects of free shock on the baseline lick rate of Groups FS1 and FS2. Brimer \& Kamin (1963) found that noncontingent free shock given prior to CER conditioning retarded acquisition by producing supernormal ratios at the beginning of training. The preshock had suppressed the baseline bar pressing rates of their rats and the CS, therefore, acted as a Pavlovian disinhibitor, starting Ss to respond and inflating their suppression ratios. Supernormal ratios were not found when baseline responding was allowed to recover before CER training began. The supernormal ratios of Groups FS2 and PC seem also to be a result of disinhibition by the CS.

It is strange that Groups FS1 and FS2 differed so much in resisting baseline disruption by shock since both groups of rats were obtained from the same supplier and were given the same experimental treatment. Most of the Ss used in Experiment 2 were, however, observed to be very emotional, i.e., they squealed, defecated, and urinated when handled and, very unlike other Ss used in this research, persisted in these behaviors not only through this experiment but through another study using the same apparatus and, finally, in a subsequent maze study conducted for an undergraduate students' laboratory. The maze experiment had to be terminated because most of the Ss soon started avoiding the goal boxes where they were rewarded with food and handled by the students.

If we accept the reality of the effect of shock shown by the difference between the FSI and SR groups, there still remains the problem of the nonrepresentativeness-of Group FS1 during testing. Clearly the FS1 Ss whose data were accepted from the testing session were selected for their ability to keep responding after a number of shocks. What of the Ss who stopped licking altogether? Annau \& Kamin (1961) assign zero suppression ratios to Ss who do not respond because they find that these Ss have low suppression ratios when they finally do begin to respond. If the nonresponders in the present study would have had low ratios during testing, the procedure of disregarding them would bias the results against the enhancing effect of noncontingent shock. Unfortunately, our data indicate that nonresponders do not necessarily have low suppression ratios when they begin to respond.

Baseline suppression was also a problem in another regard. To allow recovery of baseline responding for Ss receiving shocks before testing in this type of design, it is necessary to deliver the CS a fairly long time after the last shock. This delay may attenuate any enhancement produced by shock-induced fear; Baum (1967) has shown in a free operant avoidance shuttle situation with dogs that if a 17.5 min rest session is given between the last free shock and the beginning of the shuttle extinction session, the avoidance rate is markedly less enhanced than if the session follows immediately after shock.

It is concluded that if stable baseline response rates are maintained, noncontingent shocks temporarily stop extinction of the CER. The failure of Quinsey \& Ayres (1969) to arrest CER extinction with free CSs can be taken as evidence against a motivational explanation for the facilitation (or arrest of extinction) of a partially extinguished CER because of the finding that arrest can be obtained in the present paradigm. The interpretation is complicated, however, by the fact that the FSI group was selected for its ability to lick soon after shock, whereas SR Ss in the present experiment and Ss in Quinsey \& Ayres' (in press) experiment were not.

\section{REFERENCES}

ANNAU, Z., \& KAMIN, L. J. The conditioned emotional response as a function of intensity of the US. Journal of Comparative \& Physiological Psychology, 1951, 54, 428-432.

BAUM, M. Perseveration of fear measured by changes in rate of avoidance responding in dogs. Canadian Journal of Psychology, 1967, 21, 535-548.

BRIMER, C. J., \& KAMIN, L. J. Disinhibition, habituation, sensitization and the conditioned emotional response. Journal of Comparative \& Physiological Psychology, 1963, 56, 508-516.

HOFFMAN, $H$. S. The stimulus generalization of conditioned suppression. In D. I. Mostofsky (Ed.), Stimulus generalization. Stanford: Stanford University Press, 1965. Pp. 356-372.

QUINSEY, V. L., \& AYRES, J. J. B. The effect of CS-induced fear on a partially extinguished CER. Psychonomic Science, 1969, 14, 242, 244. NOTE

1. This study represents part of Vernon L. Quinsey's M.S. thesis. It was done under John J. B. Ayres' direction and was partially supported by a grant to him from the Faculty Research Council of the University of Massachusetts.

\section{(Continued from page 212)}

thresholds as measured by escape conditioned behavior. It is apparent that the major overall effect of deprivation was to increase the latencies. Thus, deprivation appears to increase the stimulus threshold, at least the threshold associated with electric shock.

\section{REFERENCES}

BLANCHARD, R. J., \& BLANCHARD, D. C. Food deprivation and reactivity to shock. Psychonomic Science, 1966, 4, 317-318.
BLANCHARD, R. J., HAYASHI, M., \& REYES, G. Water deprivation and shock threshold. Psychonomic Science, 1968, 10, 169-170.

CAMPBELL, B. A., \& SHEFFIELD, F. D. Relation of random activity to food deprivation. Journal of Comparative \& Physiological Psychology, $1953,46,320-322$.

GRIFFITHS, W. J. Effect of food and water deprivation on shock tolerance of albino rats. Psychological Reports, 1962, 11, 163-166. NOTE

1. This study was supported in part by Grant MH 13309-01 from the National Institute of Mental Health. 